\title{
Thermal destratification in a cylindrical packed bed $\dagger$
}

\author{
DOUGLAS W. STAMPS $\ddagger$ and JOHN A. CLARK \\ Department of Mechanical Engineering and Applied Mechanics, University of Michigan,
} Ann Arbor, MI 48109, U.S.A.

\begin{abstract}
Thermal destratification was observed in a cylindrical packed bed $62 \mathrm{~cm}$ high and $37.5 \mathrm{~cm}$ in diameter filled with $12.6 \mathrm{~mm}$ diameter glass spheres and saturated with air. The boundaries were impermeable and covered with $10.2 \mathrm{~cm}$ of either polystyrene or fiberglass insulation except in one experiment where the top surface was free and uninsulated. An apparent thermal diffusivity was calculated from the data assuming conduction only and indicated that natural convection must have a role in thermal destratification. A flow pattern consistent with the measured axisymmetric temperature field suggests that heat transfer through the sides may be important in the destratification process.
\end{abstract}

\section{INTRODUCTION}

THE PROCESS of adding energy to a packed bed thermal storage device is known as charging. Normally during charging, the flow of a hot fluid is downward through the bed. If the inlet temperature of the fluid is constant, a thermal wave with a quasi-step function travels downward. If the flow stops before the wave reaches the bottom of the bed, that is, the bed is not fully charged, the bed is thermally stratified at the end of the charging process. A thermally stratified bed may also result whenever there is a time-varying inlet fuid temperature, a common condition. Energy is recovered by reversing the flow of the working fluid through the bed.

Often there is no immediate demand for the energy stored in the packed bed after the charging process. This results in a period between the charging and recovery processes in which there is no net flow through the bed. During this thermal degradation period, there is a loss of total available energy in the bed due to thermal destratification. Destratification results from conduction and, under certain conditions, natural convection. At the end of charging for downward flows for the case in which the inlet fluid temperature is constant, the temperature inside the bed increases monotonically from the bottom to the top. This is an inherently stable temperature distribution at the end of charging with respect to natural convection since the fluid density increases uniformly with depth. The same is true when the charging fluid has a time-varying inlet temperature that increases with time. For the case in which there is a maximum in the inlet fluid temperature, however, the density will increase with height in the upper region of the

† Dedicated to Professor Dr.-Ing. Dr.-Ing.e.h. Ulrich Grigull.

† Current address: Innovative Technology Applications Division, Sandia National Laboratories, Albuquerque, NM 87185, U.S.A. bed, thus creating a potentially unstable condition in this region of the bed.

A solar energy collection system is a common example of a device that will charge a packed bed with a time-varying inlet fluid temperature. During the charging mode, the temperature of the working fluid flowing from the collector, and hence the temperature of the fluid entering the bed, increases from morning to a maximum around solar noon and then decreases during the afternoon. At the end of the charging mode, this yields a stratified bed in which the temperature increases from the bottom to a maximum approximately in the middle of the bed and decreases in the upper portions of the bed. This results in denser fluid at the top of the bed and the possibility of the onset of natural convection during the period when there is no net flow through the bed. Whether natural convection will occur depends on the vertical and wall temperature gradients, the thermal properties of the fluid and solid, the bed characteristics and geometry, and the boundary conditions.

Beasley et al. [1] measured the decay of the temperature gradient, or thermocline, in a rock bed saturated with air. The rock bed was charged with the output of a solar collector under clear sky conditions. The bed dimensions were $0.712 \mathrm{~m} \times 0.562 \mathrm{~m} \times 0.927$ $m$ (28 in. $\times 22.125$ in. $\times 36.5$ in.) with the longest dimension in the vertical direction and an equivalent diameter of $34 \mathrm{~mm}$ (1.34 in.) for the rock. The vertical sides of the bed were insulated with $90 \mathrm{~mm}(3.5 \mathrm{in}$.) of vermiculite flakes filling a pine stud-wall construction bounded by $12.7 \mathrm{~mm}(0.5 \mathrm{in}$.) and $6.4 \mathrm{~mm}(0.25 \mathrm{in}$.) plywood sheets on the inside and outside walls, respectively. The top and bottom of the bed were insulated with a $12.7 \mathrm{~mm}(0.5 \mathrm{in}$.) plywood sheet and $25.4 \mathrm{~mm}$ (1.0 in.) extruded polystyrene. From their experimental data, they calculated an apparent thermal diffusivity of the bed that was nine times greater at the top of the bed than the predicted value of thermal diffusivity for an identical bed under stagnant con- 


\section{NOMENCLATURE}

$B^{*} \quad$ modified Biot number for packed beds

c specific heat $\left[\mathrm{kJ} \mathrm{kg}^{-1} \mathrm{~K}^{-1}\right]$

$g$ acceleration of gravity $\left[\mathrm{m} \mathrm{s}^{-2}\right.$ ]

$h$ heat transfer coefficient [ $\left[\mathrm{W} \mathrm{m}^{-2} \mathrm{~K}^{-1}\right.$ ]

$k$ thermal conductivity [W $\mathrm{m}^{-1} \mathrm{~K}^{-1}$ ]

$k_{\mathrm{m}}^{\circ} \quad$ effective thermal conductivity of the porous medium under stagnant conditions $\left[\mathrm{W} \mathrm{m}^{-1} \mathrm{~K}^{-1}\right]$

$n$ unit vector normal to surface of the instrumented region of the porous medium [m]

$R \quad$ reference coordinate [m]

$s \quad$ surface of the instrumented region of the porous medium $\left[\mathrm{m}^{2}\right]$

$T$ tempcrature [C]

$t$ time [s]

$U \quad$ overall heat transfer coefficient [W $\left.\mathrm{m}^{-2} \mathrm{~K}^{-1}\right]$ v volume of the instrumented region of the porous medium $\left[\mathrm{m}^{3}\right]$

$Z \quad$ reference coordinate $[\mathrm{m}]$.

Greek symbols

$\alpha_{\mathrm{a}} \quad$ apparent thermal diffusivity $\left[\mathrm{m}^{2} \mathrm{~s}^{-1}\right]$

$\alpha_{m} \quad$ thermal diffusivily of the porous medium $\left[\mathrm{m}^{2} \mathrm{~s}^{-1}\right]$

$\varepsilon \quad$ void fraction

$\rho \quad$ density $\left[\mathrm{kg} \mathrm{m}^{-3}\right]$.

$\begin{array}{cl}\text { Subscripts } \\ \text { f } & \text { fluid } \\ \text { fg } & \text { fiberglass } \\ \text { m } & \text { porous medium } \\ \text { s } & \text { solid } \\ \text { st } & \text { steel } \\ \infty & \text { ambient. }\end{array}$

ditions. This suggested that natural convection probably occurred in the upper, unstable region of the bed.

Stamps and Clark [2] later confirmed that natural convection contributed to the thermal destratification of this rock bed. A numerical model was used to calculate the unsteady three-dimensional natural convective flows in the rectangular rock bed having impervious walls with finite heat transfer. The calculations compared favorably with the data obtained by Beasley et al. [1] and showed that the air flow was downward at the vertical walls and upward at the center. Modeling the temperature destratification by thermal conduction alone was incapable of reproducing the upward shift of the maximum centerline temperature that was observed experimentally. Likewise, the experimental results could not be reproduced without recognition of finite heat transfer rates at the boundaries.

Natural convection was also observed by Dang-Vu and Martin [3] in a large rock bed thermal storage device. Their bed was $20 \mathrm{~m} \times 3.2 \mathrm{~m} \times 2.5 \mathrm{~m}(65.6$ ft. $\times 10.5 \mathrm{ft} . \times 8.2 \mathrm{ft}$.) with the largest dimension in the horizontal direction and rock diameter between 35 and $65 \mathrm{~mm}$ (1.4 and $2.6 \mathrm{in}$.). The side walls were covered with loose insulation (foamed slag balls), the top was covered with polyurethane pancls, and the entire bed was encased in ferroconcrete. The mean value of insulation around the bed was $0.22 \mathrm{~W} \mathrm{~m}^{-2}$ $\mathrm{C}^{-1}$. At the end of charging, a maximum in the centerline temperature in both the horizontal and vertical directions was measured. At the end of their experiment, they measured an upward shift in the maximum vertical centerline temperature similar to that of Beasley et al. [1]. They compared their experimental results with calculations from a three-dimensional numerical model for thermal conduction in the rock bed with finite heat transfer at the boundaries. Their model, based on thermal conduction alone, underestimated the thermal destratification and was incapable of reproducing the shift in the maximum temperature.

Jones and Golshekan [4] observed thermal destratification in a cylindrical rock bed saturated with air. The bed was approximately $0.91 \mathrm{~m}$ (36 in.) long and $0.30 \mathrm{~m}$ ( $12 \mathrm{in}$.) in diameter with the longest dimension oriented in the vertical direction and a mean equivalent spherical diameter of $24.3 \mathrm{~mm}$ (0.96 in.). The bed was insulated with an approximately $15 \mathrm{~mm}(0.6$ in.) styrofoam container on the side and approximately $22 \mathrm{~mm}(0.9 \mathrm{in}$.) of styrofoam and polystyrene rubble on the top and bottom, respectively. The temperature distribution in the rock bed after charging increased monotonically with increasing elevation. A good comparison was obtained between their experimental results and calculations using an axisymmetrical two-dimensional model for conduction only. It is reasonable to assume that the mechanism of thermal destratification in their bed, which had an inherently stable temperature distribution at the end of the charging process, is the result of conduction alone.

Sullivan et al. [5] measured the thermal destratification in a cubic rock bed partially charged with hot air at a constant initial temperature. The characteristic dimension of the bed was $1.8 \mathrm{~m}$ (70.9 in.) and two different equivalent spherical diameters were used, 18 $\mathrm{mm}(0.71 \mathrm{in}$.) and $29 \mathrm{~mm}$ (1.14 in.), respectively. The sides and bottom of the container were insulated with $90 \mathrm{~mm}$ (3.5 in.) of fiberglass filling a pine stud-wall construction lined with $13 \mathrm{~mm}(0.5 \mathrm{in}$.) gypsum-board and $13 \mathrm{~mm}(0.5 \mathrm{in}$.) plywood sheet [6]. The top was insulated with a $100 \mathrm{~mm}$ ( $3.9 \mathrm{in}$.) slab of polystyrene foam glued to a $13 \mathrm{~mm}(0.5 \mathrm{in}$.) plywood sheet. Their 
bed was charged both with the hot air flow downward, which yields an inherently stable profile, and with the hot air flow upward, which produces a potentially unstable temperature distribution. A thermal diffusivity value was estimated from the experimental results of the destratification process although details of the method were not given. By comparing this value with a value calculated from measured properties of the bed, they concluded that natural convection was not an important mechanism of thermal destratification in their bed for either direction of charging. This observation is, of course, reasonable for the case in which the temperature distribution is inherently stable after charging. Their results may also illustrate that natural convection does not necessarily contribute to thermal destratification for beds with potentially unstable profiles if conditions of thermal stability are satisfied.

The objective of this paper is to report thermal destratification in a packed bed subjected to a timevarying inlet fluid temperature during charging. Measurements are taken from a cylindrical bed filled with glass spheres and saturated with air. Part of this study is to determine whether natural convection contributes to the thermal destratification of the bed. Another part examines the effect of different boundary conditions at the top of the bed on thermal destratification within the bed.

\section{DESCRIPTION OF EXPERIMENT}

The experimental apparatus consisted of a cylindrical bed packed randomly with uniform spheres of soda lime glass $12.6 \mathrm{~mm}(0.495 \mathrm{in}$.) in diameter and saturated with air. The packed bed had a height of 62 $\mathrm{cm}$ (24.4 in.), an experimentally measured mean void fraction of $0.364 \pm 0.01$, and was contained by galvanized steel pipe having an inside diameter of 37.5 $\mathrm{cm}$ (14.75 in.) and a wall thickness of $3.18 \mathrm{~mm}(0.125$ in.). The packed bed was enclosed by thermal insulation and was suspended in quiescent air at an ambient temperature between $24.4^{\circ} \mathrm{C}\left(76.0^{\circ} \mathrm{F}\right)$ and $27.8^{\circ} \mathrm{C}$ $\left(82.0^{\circ} \mathrm{F}\right)$. The top and bottom were covered with 10.2 $\mathrm{cm}$ (4.0 in.) of polystyrene while the vertical sides were covered with $10.2 \mathrm{~cm}$ (4.0 in.) of R-11 fiberglass insulation. A schematic of the apparatus is shown in Fig. 1. Details of the bed are given by Beasley and Clark [7].

The packed bed was instrumented with 30-gage copper-constantan thermocouples in five horizontal planes to measure solid temperatures. The locations of the thermocouples are listed in Table 1. Temperatures were measured at 42 locations in the bed by placing thermocouples in the center of individual aluminum (type 7075) spheres having a volumetric heat capacity approximately equal to that of the glass spheres. The uncertainty of the temperature measurements at the center of the spheres was estimated to be $\pm 0.3^{\circ} \mathrm{C}$ $\left( \pm 0.5^{\circ} \mathrm{F}\right)$. The ratio of the thermal resistance due to convection at the surface of the sphere to that due to conduction within the sphere is greater than 1000 , which indicates that there are negligible internal temperature gradients. The thermocouples were placed in five horizontal planes, each rotated $90^{\circ}$ clockwise from the plane above it. Additionally, within each plane, the azimuthal location of each thermocouple was rotated $45^{\circ}$ counterclockwise as the radial direction increased. The placement of thermocouples in this manner was designed to detect radial and azimuthal variations in the temperature that may result from three-dimensional natural convection in the bed.

The thermocouple data were recorded by a John Fluke model $2240 \mathrm{~B}$ data logger. The programmable scanning feature of the data logger allowed the data to be collected every $2 \mathrm{~min}$ at the beginning of each experiment and was increased up to a maximum of 15 min intervals near the end when changes in the temperature of the solid occurred slowly. The data were recorded on an IBM personal computer using electronic reference junction compensation and an A/D conversion option on the data logger.

A time-varying inlet fluid temperature during the charging mode was used to produce the initial conditions for the thermal destratification experiments. The temporal variations in the inlet air temperature during charging were obtained by a heating section containing 10 heaters controlled by a variable transformer that could allow a continuous range of power up to $14.4 \mathrm{~kW}$. The experimental temperature history during charging simulates the conditions expected for a packed bed connected to a solar collector. The air was drawn through the packed bed by a blower located downstream of the bed. Upstream of the bed, the air passed through the heater section and a series of baffles. At the end of charging, the packed bed was isolated from the flow section and the top and bottom of the bed were sealed and insulated except for one experiment in which the top cover was left off. Generally less than 15 min elapsed between the end of charging and data collection for the destratification experiments.

\section{RESULTS AND DISCUSSION}

\subsection{Thermal destratification}

Thermal destratification was observed in one experiment over a period of $428 \mathrm{~min}$ in the packed bed having rigid and impermeable sides and insulated on all boundaries. Solid temperatures at the center of the spheres were measured throughout the bed and are shown in Figs. 2-6 as functions of time and position. For clarity, every tenth data point is shown. The time was arbitrarily set equal to zero when data collection began for the destratification experiment.

The initial and final vertical centerline temperature distributions are shown in Fig. 7. The symbols represent the data and the smooth curves through the data are from a cubic spline interpolation. $Z / Z_{\mathrm{MAX}}=0$ is the top of the bed. The maximum temperature was near the center, resulting in a potentially 


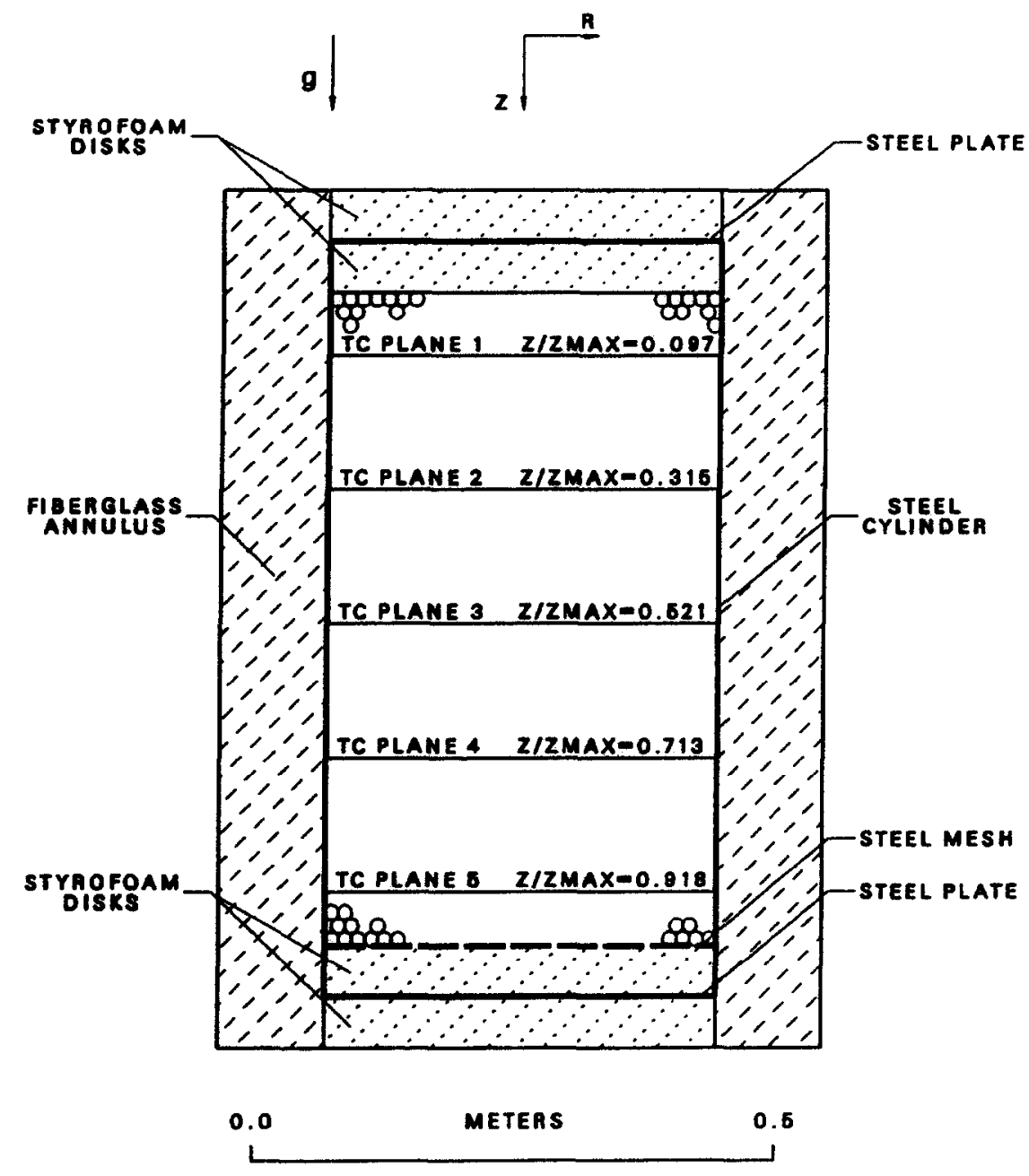

Fig. 1. Schematic of the cylindrical packed bed.

unstable region in the upper section of the bed. The possibility of natural convection contributing to the thermal destratification will be discussed in the next section.

Figures 2-6 show that there were radial variations in the bed temperature at each of the five instrumented planes at all times. Radial variations in the mean void fraction are an inherent characteristic in the near-wall regions of packed beds. The mean void fraction is largest near the wall. Once established by the charging process, the radial temperature variations persisted throughout the experiment.

Table 1. Thermocouple number of the solid temperature locations in the cylindrical packed bed

\begin{tabular}{lccccccccc}
\hline $\begin{array}{c}\text { Nondimensional } \\
\text { axial location } \\
\left(Z / Z_{\text {MAX }}\right)\end{array}$ & 0.0 & 0.237 & 0.305 & 0.492 & 0.610 & 0.745 & 1.0 & 1.0 \\
\cline { 2 - 9 } & 17 & 10 & 11 & 12 & 13 & 14 & 15 & 19 \\
\hline Plane 1 $(0.097)$ & 27 & 20 & 21 & $22 / 31$ & 23 & 24 & 25 & 29 \\
Plane 2 $(0.315)$ & 33 & 38 & 39 & 40 & 41 & $42 / 35$ & 43 & 37 \\
Plane 3 $(0.521)$ & 44 & 45 & 46 & 47 & 48 & 49 & 50 & 51 \\
Plane 4 $(0.713)$ & 52 & 53 & 54 & 55 & 56 & 57 & 58 & 59 \\
Plane 5 (0.918) & 53 & &
\end{tabular}

$\uparrow$ Thermocouple numbers 31 and 35 are at the same radial location but rotated $180^{\circ}$ from thermocouple numbers 22 and 42 , respectively.

To reconstruct the three-dimensional temperature field, the orientation of the thermocouple in each column is rotated $45^{\circ}$ in a counterclockwise direction as the radial distance increases. Each plane is rotated $90^{\circ}$ clockwise from plane 1 to plane 5 . 


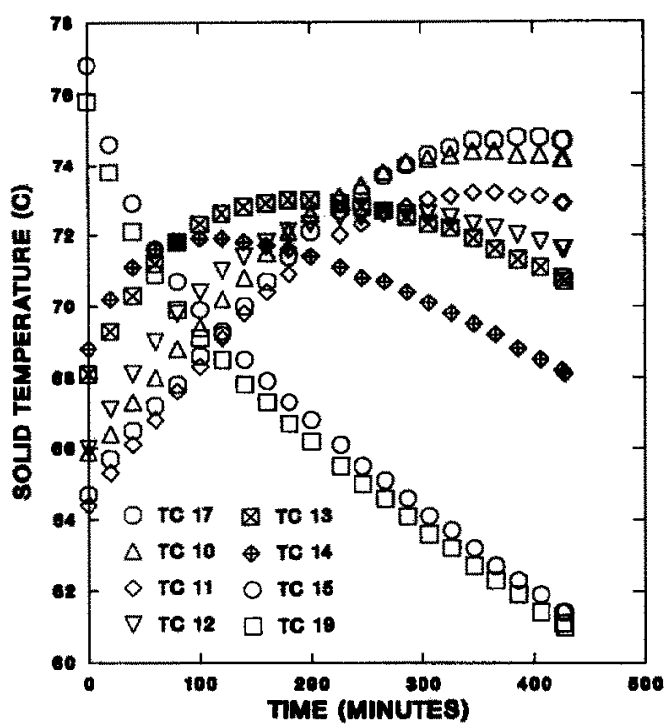

Fig. 2. Solid temperature history measurements at the center of the sphere at different radial thermocouple (TC) locations in the first instrumentation plane $\left(Z / Z_{\operatorname{Max}}=0.097\right)$. All boundaries were insulated and impermeable, as shown in Fig. 1.

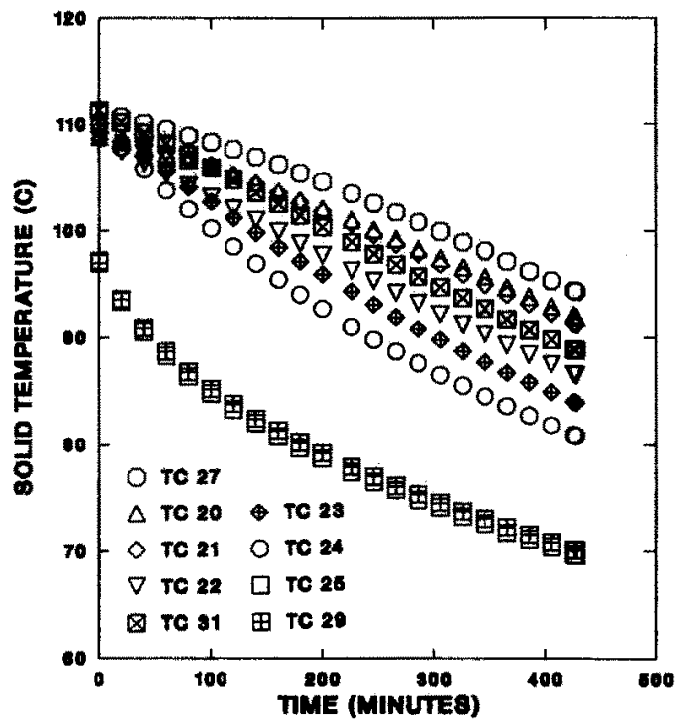

FIG. 3. Solid temperature history measurements at the center of the sphere at different radial thermocouple (TC) locations in the second instrumentation plane $\left(Z / Z_{\mathrm{MAX}}=0.315\right)$. All boundaries were insulated and impermeable, as shown in Fig. 1.

The temperature profiles in Figs. 2-6 can be used to establish that the thermal field is essentially axisymmetric throughout the entire experiment. For example, in the top instrumented plane, plane 1 in Fig. 2, thermocouples 15 and 19 were at the same radial location at the bed perimeter but oriented $45^{\circ}$ apart. At all times, the temperature difference between these two thermocouples was less than $1^{\circ} \mathrm{C}$. This was characteristic in spite of significant radial temperature

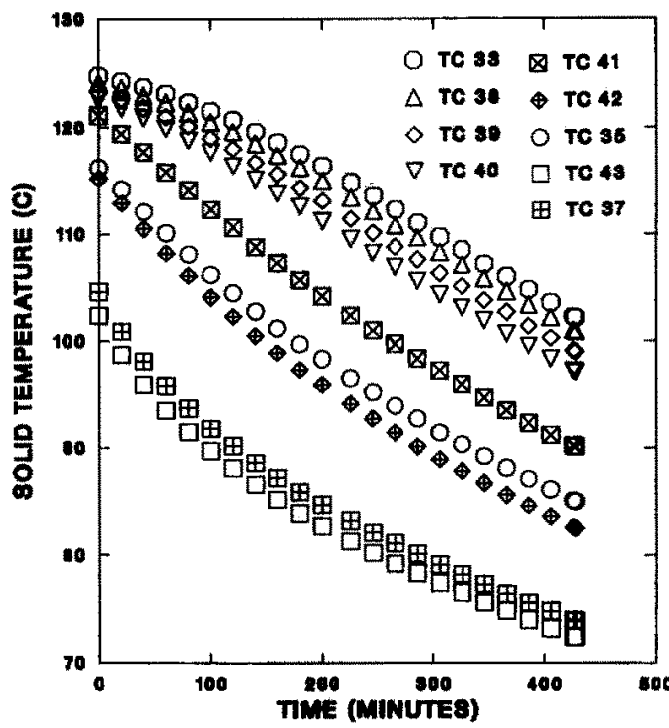

Fig. 4. Solid temperature history measurements at the center of the sphere at different radial thermocouple (TC) locations in the third instrumentation plane $\left(Z / Z_{\mathrm{MAX}}=0.521\right)$. All boundaries were insulated and impermeable, as shown in Fig. 1 .

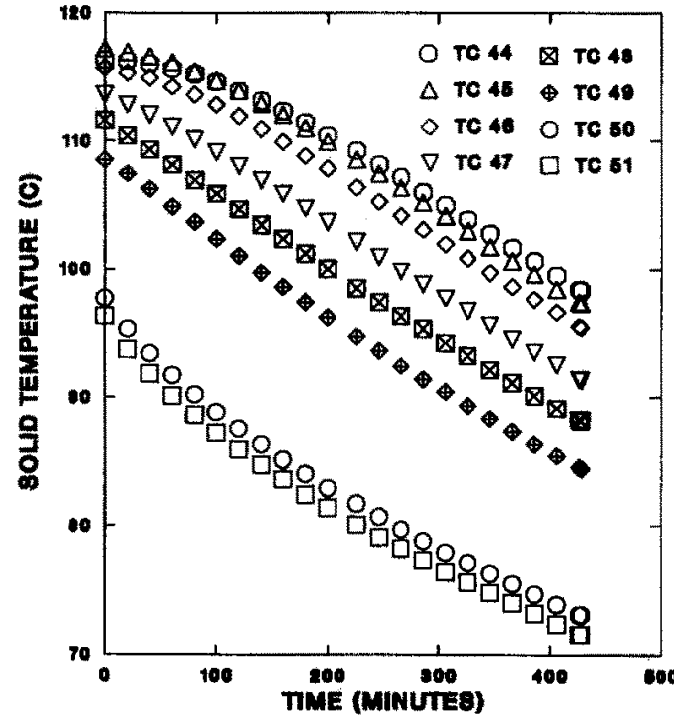

Fig. 5. Solid temperature history measurements at the center of the sphere at different radial thermocouple (TC) locations in the fourth instrumentation plane $\left(Z / Z_{\mathrm{MAx}}=0.713\right)$. All boundaries were insulated and impermeable, as shown in Fig. 1.

variations and large differences in the qualitative behavior of the temperature history of these thermocouples with respect to other thermocouples in the same plane. The same was true for all other thermocouple pairs at the bed perimeter even though the instrumented planes were rotated $90^{\circ}$ to adjacent planes. These pairs included thermocouple numbers 25 and 29, 37 and 43, 50 and 51, and 58 and 59 in planes 2-5, respectively. Also, in Fig. 3, thermocouple 


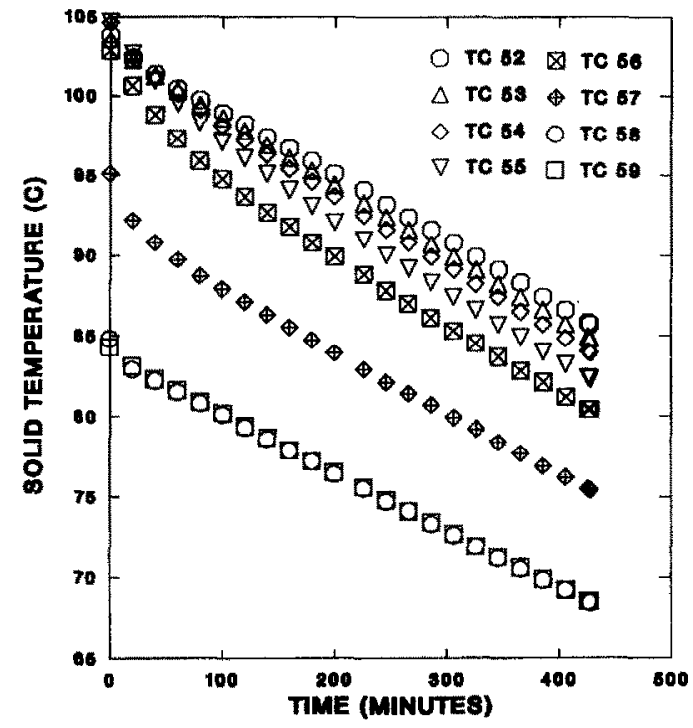

FiG. 6. Solid temperature history measurements at the center of the sphere at different radial thermocouple (TC) locations in the fifth instrumentation plane $\left(Z / Z_{\mathrm{MAX}}=0.918\right)$. All boundaries were insulated and impermeable, as shown in Fig. 1.

pair 22 and 31 were at the same radial location in plane 2 and had similar temperatures but were spaced $180^{\circ}$ apart. Likewise, the same was true for diametrically opposed thermocouple pair 35 and 42 in plane 3 shown in Fig. 4.

These data showed that thermocouples at the same radial location have similar temperatures regardless of azimuthal orientation and established that the thermal field was essentially axisymmetric. This is to be

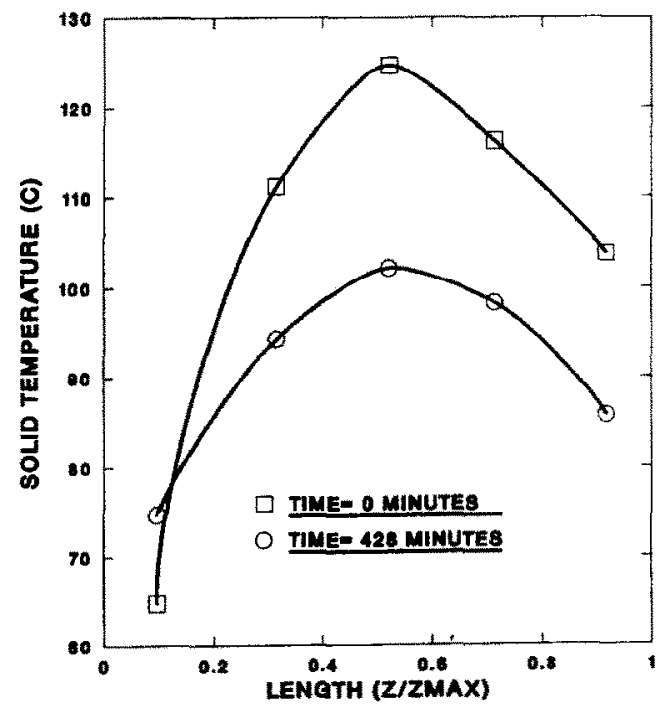

FIG. 7. Initial and final axial solid temperature distributions along the centerline of the packed bed. All boundaries were insulated and impermeable, as shown in Fig. 1. Symbols represent data and the continuous lines are cubic spline interpolation curve fits through all data points. expected since the flow field was uniform during charging, thus producing an initially axisymmetric temperature distribution at the beginning of the experiment. Since the boundary conditions were spatially uniform, it was expected that the thermal field would remain axisymmetric unless natural convective flows, if they existed, were asymmetric.

\subsection{Apparent thermal diffusivity}

An apparent thermal diffusivity was calculated from the present data assuming no convective flow. The apparent thermal diffusivity was compared with the thermal diffusivity predicted from a correlation for an identical bed under stagnant conditions to determine if conduction was the sole mechanism con. tributing to thermal destratification in this bed.

The energy equation for time-dependent conduction in a porous medium was spatially integrated over the instrumented region of the bed. Using Green's theorem, the volume integral of the conduction term was converted to the surface integral of the heat flux at the boundary of the instrumented region. The expression for the apparent thermal diffusivity is

$$
\alpha_{\mathrm{a}}=\left[\int_{i} \partial T / \partial t \mathrm{~d} v\right] /\left[\int \partial T / \partial n \mathrm{~d} s\right]
$$

Calculating the apparent thermal diffusivity in this manner avoids the need to evaluate second derivatives of the data. Equation (1) yields a spatially averaged, time-dependent apparent thermal diffusivity. By using different functional forms to calculate the apparent thermal diffusivity, the uncertainty is estimated to be approximately $15 \%$. A discussion of this is given later.

An approximate analytical representation of the axisymmetric temperature field was used to evaluate equation (1). The temperature profile in the $z$-direction was approximated by a simple fourth-order polynomial with five unknown coefficients. Since there were five measured temperatures in the $z$-direction corresponding to the five instrumentation planes, the approximate vertical temperature profile is an exact curve fit of the data. A standard routine was used to compute the coefficients of the system of linear equations. In the radial direction, the temperature profile was approximated by a linear interpolation between each data point. The spatial derivatives in equation (1) were evaluated analytically. With respect to the time derivative in equation (1), the spatially averaged temperature was first calculated for each time step the data was recorded. The time-dependent spatially averaged temperature was approximated by a rational polynomial (ratio of second-order polynomials) using an error minimization curve fit. The maximum difference between the curve fit and the spatially averaged temperature was less than $0.1^{\circ} \mathrm{C}$. The time derivative was obtained analytically from this functional form.

An alternate functional form of the vertical tem- 
peraturc profile was also considered. The temperature was represented by a ratio of second-order polynomials having a total of five unknown coefficients. Like the simple polynomial case, this rational polynomial was an exact curve fit of the data. However, even using such different functional forms to represent the vertical temperature profile, the apparent thermal diffusivity varied by less than approximately $15 \%$. This illustrates that the apparent thermal diffusivity was not extremely sensitive to the functional form chosen to approximate the temperature profile.

The thermal diffusivity for a porous nedium under stagnant conditions is

$$
\alpha_{\mathrm{m}}^{\circ}=k_{\mathrm{m}}^{\circ} /(\rho c)_{\mathrm{m}}
$$

where $k_{\mathrm{m}}^{\circ}$ is the effective thermal conductivity of a porous medium under stagnant conditions and

$$
(\rho c)_{\mathrm{m}}=\varepsilon(\rho c)_{\mathrm{f}}+(1-\varepsilon)(\rho c)_{\mathrm{s}}
$$

is the heat capacity of the porous medium. The thermal diffusivity was calculated using the value of the properties at $85.7^{\circ} \mathrm{C}$. This corresponds to the spatially averaged initial temperature of the packed bed.

The effective thermal conductivity was calculated using the correlation proposed by Kunii and Smith [8]. It was later assessed by Ofuchi and Kunii [9], who reported average deviations between calculated and observed values to be smaller than $15 \%$. Using 1.06 $\mathrm{W} \mathrm{m} \mathrm{m}^{-1} \mathrm{~K}^{-1}$ and $0.0307 \mathrm{~W} \mathrm{~m}^{-1} \mathrm{~K}^{-1}$ for the glass and air thermal conductivities, respectively, 0.95 for the emissivity of the glass, and 0.364 for the bed void fraction, the correlation by Kunii and Smith yields a value of $0.2246 \mathrm{~W} \mathrm{~m}^{-1} \mathrm{~K}^{-1}$ for the effective thermal conductivity. This value is in close agreement with an observed value reported by Ofuchi and Kunii [9] for a glass-air packed bed with particle diameter and void fraction similar to the present study. Using $2482 \mathrm{~kg}$ $\mathrm{m}^{-3}$ and $0.973 \mathrm{~kg} \mathrm{~m}^{-3}$ for the density of the glass and air, respectively, and $0.860 \mathrm{~kJ} \mathrm{~kg}^{-1} \mathrm{~K}^{-1}$ and $1.010 \mathrm{~kJ}$ $\mathrm{kg}^{-1} \mathrm{~K}^{-1}$ for the specific heat of the glass and air, respectively, the heat capacity of the porous medium defined in equation (3) was calculated to be $1358 \mathrm{~kJ}$ $\mathrm{m}^{-3} \mathrm{~K}^{-1}$. Using equation (2), the thermal diffusivity for the present bed under stagnant conditions was calculated to be $1.65 \mathrm{E}-07 \mathrm{~m}^{2} \mathrm{~s}^{-1}$.

The ratio of the time-dependent spatially averaged apparent thermal diffusivity obtained from the data and the thermal diffusivity for the present bed under stagnant conditions obtained from the correlation is shown in Fig. 8. For clarity, not all of the values are plotted. Initially the apparent thermal diffusivity is approximately 2.6 times larger than the thermal diffusivity of the bed under stagnant conditions and continuously decreases throughout the experiment. These data suggest that the apparent thermal diffusivity is larger because the thermal destratification observed in the bed is assisted by natural convection. The mechanism of thermal destratification is not a result of conduction alone. This is in agreement with the con-

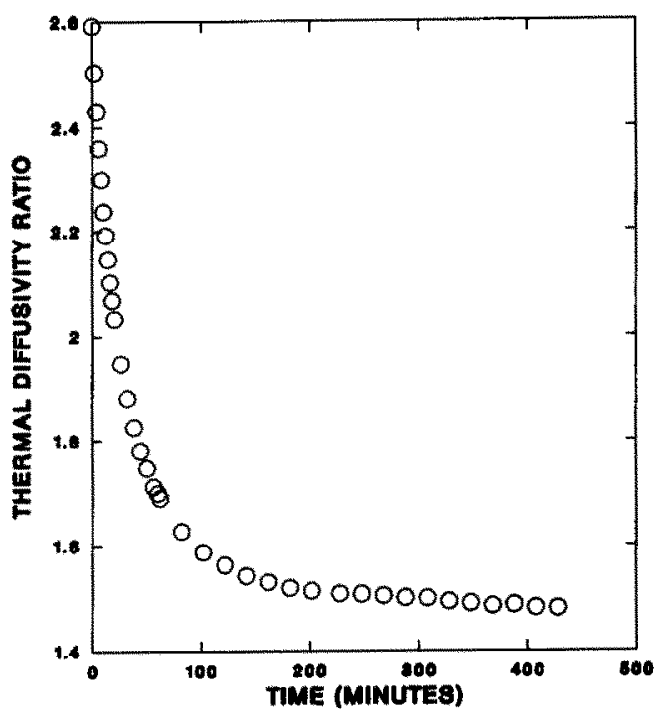

FiG. 8. Temporal variations in the ratio of the spatially averaged apparent thermal diffusivity and the predicted thermal diffusivity for an identical bed under stagnant conditions. The apparent thermal diffusivity was calculated from the experimental data in Figs. 2-6 assuming conduction only in the bed.

clusions of Stamps and Clark [2] for a bed with different geometry and characteristics.

Since the temperature field remains approximately axisymmetric throughout the experiment, a possible flow pattern in this bed involves a descending flow on all vertical sides and an ascending flow at the center. This suggestion is based on the calculations by Stamps et al. [10] for a cube of porous medium with finite heat transfer on the vertical sides. This work showed that such a flow pattern was possible given a suffciently large heat loss through the boundaries.

The side wall heat transfer can be characterized by a modified Biot number for the packed bed, defined as $B^{*} \equiv U R_{1} / k_{\mathrm{m}}$. The overall heat transfer coefficient, $U$, for the side of the cylindrical packed bed is

$$
\begin{aligned}
U=\left[\left(R_{1} / k_{\mathrm{st}}\right) \ln \left(R_{2} / R_{1}\right)+\right. & \left(R_{1} / k_{\mathrm{fg}}\right) \ln \left(R_{3} / R_{2}\right) \\
& \left.+\left(R_{1} / R_{3}\right)\left(1 / h_{\infty}\right)\right]^{-1}
\end{aligned}
$$

where $R_{1}, R_{2}$, and $R_{3}$ are the radii at the inside diameter of the steel pipe, the outside diameter of the steel pipe, and the outside diameter of the fiberglass insulation, respectively. Using values of $0.187,0.190$, and $0.292 \mathrm{~m}$ for $R_{1}-R_{3}$, respectively, 60.5 and $0.038 \mathrm{~W}$ $\mathrm{m}^{-1} \mathrm{~K}^{-1}$ for the thermal conductivities of mild steel and fiberglass, respectively, and an assumed value of $5 \mathrm{~W} \mathrm{~m}^{-2} \mathrm{~K}^{-1}$ for the external heat transfer coefficient, the overall heat transfer coefficient is $0.446 \mathrm{~W} \mathrm{~m}^{-2}$ $\mathrm{K}^{-1}$. Using this value and the one calculated earlier for the effective thermal conductivity for the packed bed, the modified Biot number is estimated to be 0.371 .

Although results from the cylindrical packed bed cannot be compared directly to results for other 
geometries, the value of $B^{*}$ indicates the flow pattern suggested earlier is possible. For cubic geometries [10], the natural convective flow pattern was altered when $B^{*}$ was greater than approximately 0.1 . For the experimental results obtained in a rectangular bed [1, 2], the fluid was calculated to flow down the vertical sides and up the center when $B^{*}=1.09$. This flow pattern appears to be reasonable for the present experiment and is consistent with the results from other geometries $[1,2,10]$. It is not clear what effect the radial temperature gradients within the packed bed may have in either establishing or maintaining natural convection. For example, this flow pattern was calculated to occur even when the temperature was uniform in the radial direction for cubic geometries [10]. Perhaps the radial variations in the mean void fraction are more important since the permeability is largest near the wall.

It may be possible that heat loss resulting from the difference between the ambient and wall temperatures can become more important in determining the flow pattern in the bed than the temperature difference in the potentially unstable region in the upper part of the bed. This has important implications to solar thermal energy storage and suggests that natural convection may also contribute to thermal destratification in packed beds charged with 'inherently' stable temperature profiles if insufficiently insulated.

\subsection{Effect of boundary conditions}

Two experiments were conducted to determine the effect of different boundary conditions at the top of the packed bed. In one experiment, all boundaries were insulated and impermeable, as shown in Fig. I. In the other experiment, the top surface stecl plate and insulation were removed resulting in a free and uninsulated surface at the top of the porous medium. All other boundary conditions were identical to fig. 1 .

The two experiments had similar initial conditions and duration. Both tests had an initial potentially
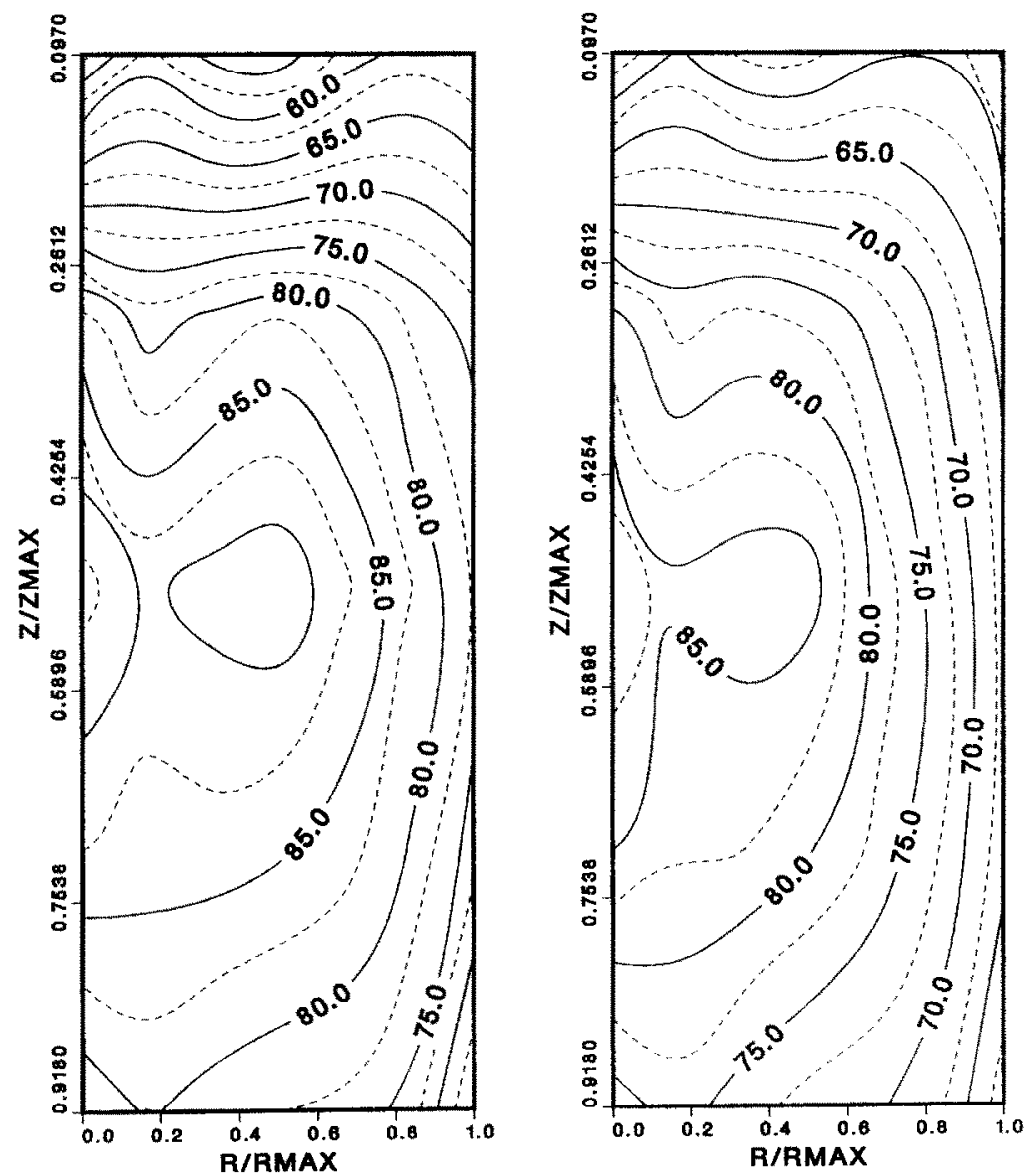

Frg. 9. Isotherms (in units of ${ }^{\circ} \mathrm{C}$ ) in the instrumented section of the cylindrical packed bed. All boundaries were impermeable and insulated, as shown in Fig. 1. Because of axisymmetry, only the temperatures between the centerline and the wall are shown in the radial direction. 

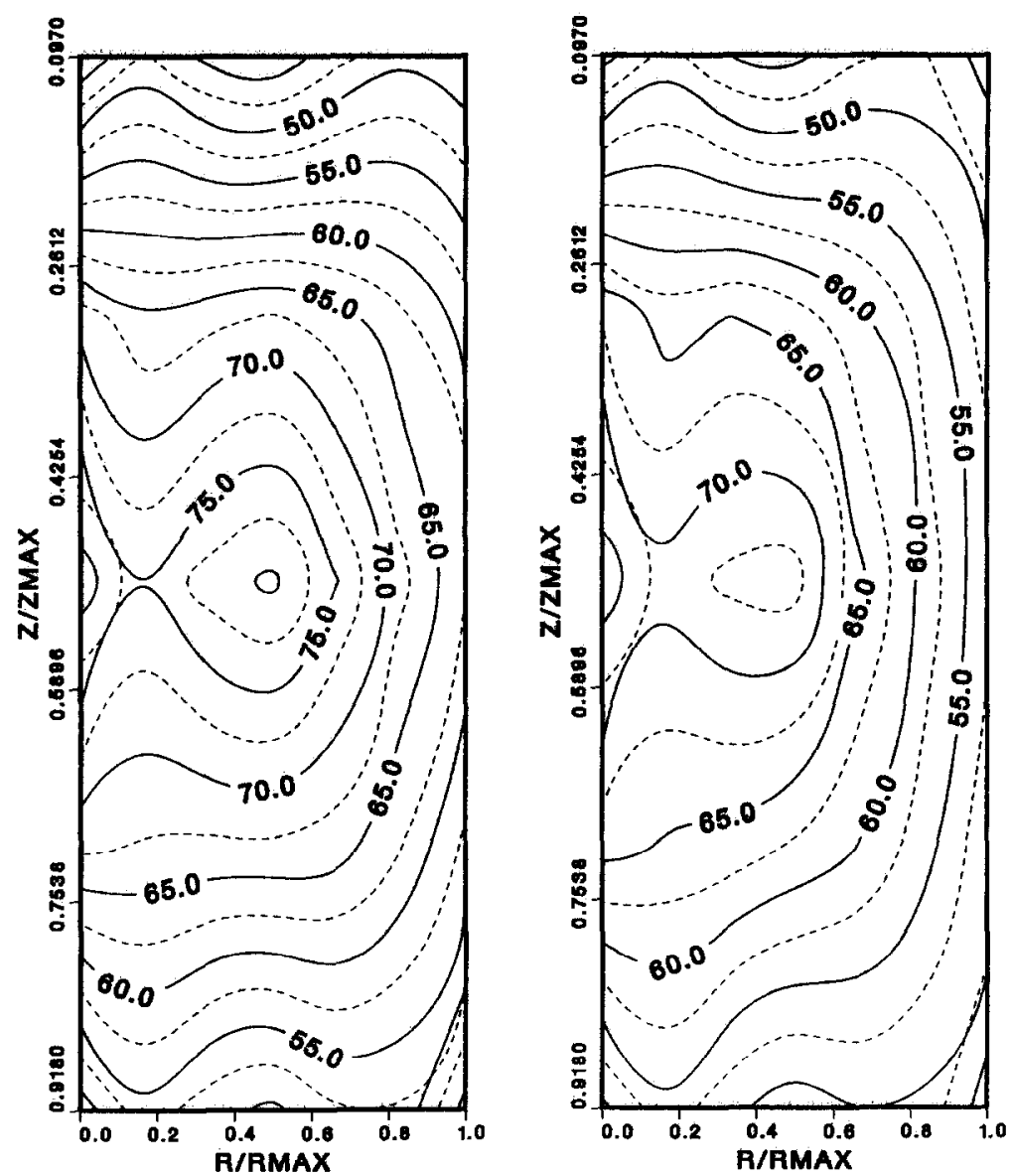

FIG. 10. Isotherms (in units of ${ }^{\circ} \mathrm{C}$ ) in the instrumented section of the cylindrical packed bed. All boundaries were impermeable and insulated, as shown in Fig. 1, except the top surface, which was free and uninsulated. Because of axisymmetry, only the temperatures between the centerline and the wall are shown in the radial direction.

unstable axial temperature profile similar to that shown in Fig. 7. The axial temperature differences between planes 1 and 3 were $42.1^{\circ} \mathrm{C}$ and $39.6^{\circ} \mathrm{C}$ for the impermeable and insulated case and the free and uninsulated case, respectively. Data were collected for a duration of $144 \mathrm{~min}$ for each experiment.

The isotherms of the solid temperatures at the center of the spheres of the two experiments at the initial and final times are shown in Figs. 9 and 10. Figure 9 shows data for the case in which all boundaries were insulated and impermeable, as shown in Fig. 1. Figure 10 is for the case in which the top surface was free and uninsulated and all other boundaries were insulated and impermeable, as also shown in Fig. 1. The contour plots in Figs. 9 and 10 cover the range in the vertical direction from thermocouple planes 15 , which corresponds to a nondimensional distance, $Z / Z_{\mathrm{MAX}}$, between 0.097 and 0.918 , respectively. Since the temperature field is axisymmetric, the radial temperatures are plotted from the axis $\left(R / R_{\mathrm{MAX}}=0.0\right)$ to the bed boundary $\left(R / R_{\operatorname{MAX}}=1.0\right)$. Both Figs. 9 and 10 are plotted according to the geometric scale of the packed bed. The average difference between the temperatures in the contour plots and the experimentally measured temperatures is less than $3 \%$.

No significant qualitative differences are observed in the temperature fields between Figs. 9 and 10 in spite of two different sets of top surface boundary conditions. This may provide additional support that side wall heat transfer is important in the thermal destratification process. These data can be useful to assess models that predict two- or three-dimensional thermal destratification in cylindrical packed beds. These data can be especially useful in assessing the capability of different models to predict the effect of boundary conditions since the present data have nearly identical initial and boundary conditions. The only difference is that the two experiments had different conditions at the top surface. 


\section{SUMMARY}

Thermal destratification was observed in a cylindrical packed bed $62 \mathrm{~cm}$ high and $37.5 \mathrm{~cm}$ in diameter. A potentially unstable temperature profile was used for the initial temperature distribution. Experiments having different boundary conditions at the top surface of the bed were conducted.

An apparent thermal diffusivity was calculated using the experimental data and based on the assumption that destratification was a result of conduction losses only. The apparent thermal diffusivity was found to be as large as 2.6 times that of the thermal diffusivity predicted for an identical bed under stagnant conditions. Based on this comparison, thermal destratification in this bed appears to be a result of both diffusive and convective effects.

The bed was charged with axisymmetric temperature and flow fields and maintained its axisymmetry throughout the duration of the destratification experiment. Since natural convection appears to play an important role in the thermal destratification process, a possible flow mode that is consistent with the axisymmetric conditions is one in which the fluid flows down the sides and up the center. This flow has been shown to be possible when heat transfer through the vertical sides is sufficiently large. For this condition, heat transfer through the vertical sides may he as important in destabilizing the bed as is the potentially unstable initial vertical temperature distribution in the upper portion of the bed.

Two experiments were conducted with nearly identical initial and boundary conditions. The only difference was that in one experiment the top surface of the packed bed was impermeable and insulated and, in the other experiment, the top surface was free and uninsulated. No significant differences in the quali- tative behavior of the temperature field were observed between these two boundary conditions.

Acknowledgements--We are grateful to Prof. D. E. Beasley for the construction of the apparatus and initial guidance in the experimentation. We also appreciate the useful comments concerning the interpretation of the data by Dr. S. R. Tieszen. Finally, we are grateful to Dr. A. W. Reed for the technical discussions on the calculation of the apparent thermal diffusivity.

\section{REFERENCES}

1. D. E. Beasley, J. A. Clark and M. J. Holstege, Observations on the decay of a thermocline in a rock bed with no net fluid flow, J. Solar Energy Engng 107, 50-53 (1985)

2. D. W. Stamps and J. A. Clark, Unsteady thermocline degradation in a fluid-saturated, porous medium, Int. $J$. Heat Mass Transfer 29, 1063-1070 (1986)

3. C. Dang-Vu and J. Martin, Experimentation on a long term rock-bed thermal storage, First European Community Conf. on Solar Heating, Amsterdam, 30 April 4 May, Reidel, The Netherlands (1984)

4. B. W. Jones and M. Golshekan, Destratification and other properties of a packed bed heat store, Int. J. Heat Mass Transfer 23, 351-359 (1989).

5. H. F. Sullivan, K. G. T. Hollands and E. C. Shewen, Thermal destratification in rock beds, Solar Energy 33, 227-229 (1984).

6. K. G. T. Hollands, H. F. Sullivan and E. C. Shewen, Flow uniformity in rock beds, Solar Energy 32, 343-348 (1984)

7. D. E. Beasley and J. A. Clark, Transient response of a packed bed for thermal energy storage, Int.J. Heat Mass Transfer 27, 1659-1669 (1984).

8. D. Kunii and J. M. Smith. Heat transfer characteristics of porous rocks, A.I.Ch.E. Jl 6, 71-78 (1960).

9. K. Ofuchi and D. Kunii, Heat-transfer characteristics of packed beds with stagnant fluid, Int. J. Heat Mass Transfer 8, 749-757 (1965).

10. D. W. Stamps, V. S. Arpaci and J. A. Clark, Unsteady three-dimensional natural convection in a fluid-saturated porous medium, J. Fluid Mech. 213, 377--396 (1990).

\section{DESTRATIFICATION THERMIQUE DANS UN LIT FIXE CYLINDRIQUE}

Résumé-On observe la déstratification thermique dans un lit fixe cylindrique de $62 \mathrm{~cm}$ de hauteur et 37,5 $\mathrm{cm}$ de diamètre, rempli de sphères en verre de $12,6 \mathrm{~mm}$ de diamètre et saturé d'air. Les frontières sont imperméables et couvertes de $10,2 \mathrm{~cm}$ d'isolant soit en polystyrène, soit en fibre de verre, excepté dans une expérience où la surface supérieure était libre et sans isolation. Une diffusivité thermique apparente est calculée à partir des données en supposant la conduction seule et on constate que la convection naturelle peut avoir un rôle dans la déstrification thermique. Une configuration d'écoulement, compatible avec un champ de température axisymétrique mesuré, suggère que le transfert thermique à travers les côtés peut être important dans le mécanisme de la déstrification. 


\section{AUFLÖSUNG EINER THERMISCHEN SCHICHTUNG IN EINEM ZYLINDRISCHEN FESTBETT}

Zusammenfassung-Die Aufösung einer thermischen Schichtung wird in einem zylindrischen Festbett (Höhe $62 \mathrm{~cm}$, Durchmesser 37,5 cm) aus luftgesättigten Glaskugeln (Durchmesser 12,6 mm) beobachtet. Die Berandungen sind undurchlässig und mit einer 10,2 cm dicken Isolierung aus Polystyrol oder Glasfiber bedeckt, ausgenommen ein Experiment mit freier nichtisolierter Oberfläche. Unter der Annahme reiner Wärmeleitung wurde aus den Meßdaten eine scheinbare Temperaturleitfähigkeit berechnet. Das Ergebnis weist darauf hin, daß natürliche Konvektion bei der Auflösung der thermischen Schichtung eine Rolle spielen muß. Ein Strömungsmuster, das mit dem gemessenen achsensymmtrischen Temperaturfeld übereinstimmt, weist darauf hin, daß möglicherweise der Wärmedurchgang durch die Seitenwände wichtig für die Auflösung der thermischen Schichtung sein kann.

\section{ТЕПЛОВАЯ ДЕСТРАТИФИКАЦИЯ В ЦИЛИНДРИЧЕСКОМ ПЛОТНОМ СЛОЕ}

Апотащв-Тепловая дестратифнкация наблюдалась в цилиндрическом плотном слое высотой 62 см и диаметром 37,5 см, заполненном стехлянными шаригамн днаметром 12,6 мм в насьщенвом воздухом. Гранғщы были непроницаемыми и похрывались изолящией из полистирола или стехловолокна толшиной $10,2 \mathrm{~cm}$ за исключением эксперимента со свободной и неизолированной верхней поверхностью. Эффегтивная температуропроводность определялась по данным, учнтывакощтм только теплопроводность. Результаты показали, что на тепловую дестратвфнкашно влияет естественная конвекция. Струхтура течения, соответствующая найденному ососпметрнчному температурному полю, позволяет предполохить, что теплоперенос через боковые стенхи может итрать вахную роль в процессе дестратификация. 